This item was submitted to Loughborough's Research Repository by the author.

Items in Figshare are protected by copyright, with all rights reserved, unless otherwise indicated.

\title{
Design and implementation of a low-cost phasor measurement unit: a comprehensive review
}

PLEASE CITE THE PUBLISHED VERSION

https://doi.org/10.1109/BalkanLight.2018.8546936

PUBLISHER

(C) IEEE

VERSION

AM (Accepted Manuscript)

LICENCE

CC BY-NC-ND 4.0

\section{REPOSITORY RECORD}

Schofield, Dave, Francisco M. Gonzalez-Longatt, and Dimitar Bogdanov. 2019. "Design and Implementation of a Low-cost Phasor Measurement Unit: A Comprehensive Review”. figshare. https://hdl.handle.net/2134/35093. 


\section{Design and Implementation of a Low-Cost Phasor Measurement Unit: A Comprehensive Review}

\author{
Dave Schofield \\ Surrey Satellite Technology Limited \\ Guildford, United Kingdom \\ D.Schofield@sstl.co.uk
}

\author{
Francisco Gonzalez-Longatt \\ Centre for Renewable Energy Systems \\ Technology (CREST) \\ Loughborough University \\ Loughborough, United Kingdom \\ fglongatt@fglongatt.org
}

\author{
Dimitar Bogdanov \\ Faculty of Electrical Engineering \\ Technical University - Sofia \\ Sofia, Bulgaria \\ dbogdanov@tu-sofia.bg
}

\begin{abstract}
The complexity of the contemporary electrical power systems imposes challenges in aspect of monitoring, protection and control. In order to obtain high speed of response, wide area effect and prices synchronization, the grid control functions can be benefited by the implementation of Phasor Measurement Units (PMU). The paper is aimed to make a review of the commercial implementation of Phasor Measurement Units and then open source based implementations (open architecture hardware and software). This paper focuses on standard implementations; as a consequence the concept of virtual PMU is not discussed here.
\end{abstract}

Keywords- Phasor Measurement Units (PMU), review, standards, options, low cost, comparison

\section{INTRODUCTION}

The complexity of power systems is increasing more and more, mainly caused by the rapidly increasing interconnection and integration of new technologies [1]. The complexity has increased in the last decade caused by the massive integration of non-conventional power generation technologies such as wind power, solar photovoltaic, etc., and other power converter-based technologies [2]: High voltage direct current (HVDC) transmission systems, electric vehicle (EV) charger stations and battery energy storage systems (BESSs).

The integration of power electronic converters (PECs) based electrical energy generation technologies is making the power system dynamic faster and imposes new operation challenges to the system operator [3]. As a consequence, enhanced monitoring and control of the complex power grids operation has become a system operator's high priority. The necessity of advanced grid monitoring was the motivation behind the Network Security Monitoring (NSM) system. Traditionally, monitoring of the steady-state performance of an electrical power system has been achieved by the Supervisory Control and Data Acquisition (SCADA) systems [4].

Digital SCADA systems (1965 to the present) samples the electrical values typically in every one to ten seconds; it is sufficient for monitoring power systems in stable operation conditions, but this resolution is not good enough to capture the dynamic process in case of grid disturbances. Data fault recorders (DFRs) register information about power-system disturbances and these have the capacity to collect data when triggered by specific conditions detected in the power system. The DFR provides greater visibility and sample resolution as well (several thousand samples per second), and they are especially useful in the analysis of pre-fault / postfault conditions and forensic engineering.
The catastrophic blackout of 1965 in the North-Eastern power grid in the United States imposed preconditions for the development of Energy Management Systems (EMS), which also depended upon wide area measurements to perform steady state estimation and other real-time control tasks. The development of the Symmetrical Component Distance Relay [5] (SCDR) in the early 1970s defined the origin of modern phasor measurement systems. Synchronized Phasor Measurement Units (PMU) were introduced in the mid-1980s [6], [7] as a more efficient and dependable measurement solution for the power system monitoring. The PMU is a powerful device which measures the electrical waves on the electrical power system using a common time source for synchronisation by Global Positioning System (GPS) satellites and respectively receiving Universal Time Coordination (UTC) signals.

Wide area monitoring systems (WAMS) help power system operators continuously analyse all the features of an extensive power network in real time. It is fundamentally based on the new data acquisition technology of PMUs and allows monitoring of transmission system conditions over large areas for detecting and further counteracting grid instabilities. The modern evolution of WAMS includes Wide area monitoring protection and control (WAMPAC), Widearea situational awareness (WASA), etc. The typical WAMS consists of three key components: (i) data acquisition, id est PMU, (ii) data delivery or data transmitting, and data processing which mainly deals with the data management system (WASA), etc.

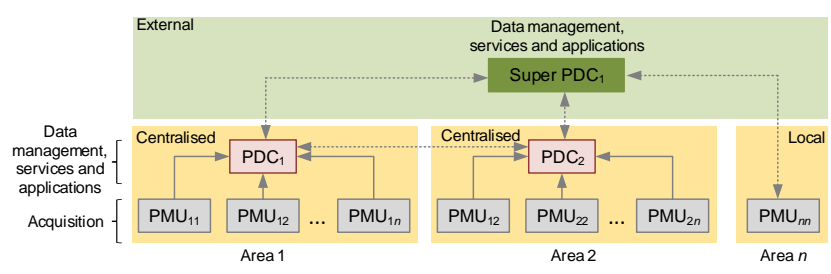

Fig. 1. Generic architecture of phasor network architecture, suitable for WAMPAC.

Fig. 1 shows a generic architecture of a phasor network architecture, where PMUs process measurements (voltages and currents) and provide a stream of time-synchronized phasor data [8], Phasor Data Concentrator (PDC) is a computer that receives the phasor data from the PMU and produces a real-time, time-aligned output data stream; finally, super-data concentrators (SPDCs) is a central PDC that receives, processes and sends out data/information to applications and/or storage and forms signals for control/protection.

To ensure that the phasor measurements from all the PMUs can be accurately compared, the data from each PMU 
can be supplied with an accurate time index, such as that obtained from a Global Positioning System (GPS), source Universal Time Coordinated (abbreviated to UTC) time stamp. These time-correlated measurements are referred to as synchrophasors.

This paper presents a comprehensive review of the options for development and implementation of a low-cost PMU. The paper is structured as follows: Section II presents the main aspects of the PMU fundamentals and standardization. Section III presents a comprehensive review of the actual development and implementation of low-cost solutions for PMU, and Section IV presents the main conclusion, findings and future research directions on costimplementability analysis of PMUs applications.

\section{PMU FUNDAMENTALS AND STANDARDIZATION}

Data acquisition and processing are rapidly evolving in the context of power systems, as a consequence, there is a need to keep up to date the mechanism to ensure the users with records, time-tags, data transition, and analysing mechanisms of the power system phasor quantities in real time. Standardisation is a critical element in order to guarantee a uniform performance among the data acquisition devices from different manufacturers. This section presents the fundamentals concepts of PMU and aspects of standardization.

\section{A. PMU Definition}

The PMU is defined as a "device that produces synchronized phasor, frequency, and rate of change of frequency (ROCOF) estimates from voltage and/or current signals and time synchronizing signal" [9]. The PMU uses the concept of phasor representation as introduced by the German-American electrical engineer and mathematician Charles Proteus Steinmetz [10].

Many standards have been developed in order to allow the power industry to store or transmit time-tag data, exempli gratia IEEE Std C37.111-1991 [11], IEEE Standard Common Format for Transient Data Exchange (COMTRADE) for Power Systems (ANSI), for file storage; and IEC 61850 [12] Communication networks and systems for power utility automation for mainly substation communications. However, the first PMU standard was the IEEE 1344-1995, Synchrophasor Standard [13], It is an extension of the Inter-range instrumentation group time codes (commonly known as IRIG time codes), and uses Network Time Protocol (NTP) format for time synchronisation.

The IEEE 1344-1995, Standard for Synchrophasors for Power Systems, addresses the synchronisation of data sampling, data-to-phasor conversions and formats for timing input and phasor data output from a PMU. However, this standard is limited to scope in the aspect of addressing the PMU response time, accuracy, hardware, software, or the most essential process: computing phasors. This standard includes the definition of data transmission formats for realtime data reporting. Also, the IEEE 1344-1995 considers messaging between PMUs and another device, i.e. data recording application, but it does not support transmission hierarchy.

In order to guarantee interoperability across networks, the IEEE published standard C37.118 in 2005 [9]. It contains a definition for synchronised phasor measurement, the methodology of quantifying these measurements, and specifications for quality test [14]. The total vector error (TVE) was the quality indicator introduced in the IEEE C37.118-2005. Also, the standard specified accuracy requirements for a PMU considering steady-state conditions, but quickly was recognised the need for the specifications for dynamic performance of synchrophasor measurements. Finally, the IEEE C37.118-2005 stated a better definition of the frequency measurement and other few minor corrections [14].

The IEEE C37.118-2005 was finally updated in 2011 in two parts - IEEE Std. C37.118.1 [15] gives details of the estimation of the synchrophasor and certification requirements, and IEEE Std. C37.118.2 [16] gives details of how the data is to be represented and transferred. The IEEE C37.118.2-2011 includes the specifications and improved definitions for the dynamic performance of synchrophasor measurements. Also, this standard introduced two types of PMUs to ensure that the device is compatible with existing phasor data concentrators (PDCs) and visualization software: (i) M-class: primarily for steady-state measurements, similar to the requirements presented on the IEEE C37.118-2005, and (ii) P-class: dedicated to protection functionality, with fast response without filtering, having more relaxed performance but intended to capture the dynamic behavior.

The latest versions of these standards are IEEE Std. C37.118.1a-2014 [17] which is an amendment to IEEE Std. C37.118.1-2011 and IEEE Std. C37.118.2-2011 [18].

\section{B. Synchrophasor Definition}

The IEEE Std. C37.118.1a-2014 [17] defines the synchrophasor representation $(\mathbf{X})$ of a periodic signal, $x(t)=X_{m} \cos (\omega t+\phi)$ as:

$$
\mathbf{X}=\frac{X_{m}}{\sqrt{2}} e^{j \phi}
$$

where the magnitude of the synchrophasor $\left(\mathbf{X}=|X|=X_{m} / \sqrt{2}\right)$ is the RMS value of $x(t)$, and $\phi=\operatorname{angle}(\mathbf{X})$ represents the momentary phase angle relative to a cosine function at the nominal system frequency synchronized to UTC (see Fig. 2).

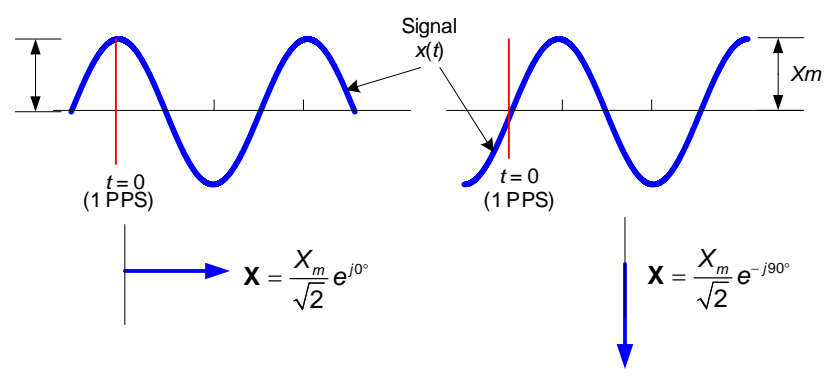

Fig. 2. Convention for synchrophasor representation.

The standard defines the frequency, $f(t)$ as:

$$
f(t)=\frac{1}{2 \pi} \frac{d \psi(t)}{d t}
$$

based on a $x(t)=X_{m} \cos [\psi(t)]$, where: $\psi(t)=\omega t+\phi$. The IEEE Std. C37.118.1a-2014 defines the ROCOF as: 


$$
\operatorname{ROCOF}(t)=\frac{d f(t)}{d t}
$$

The total vector error (TVE) was the quality indicator introduced in the IEEE. C37.118-2005, and since then has been included in the subsequent version of the standard. TVE is defined as the percentage magnitude of a vector difference between the measured $\left(\mathbf{X}_{\text {mea }}\right)$ and actual phasors $\left(\mathbf{X}_{\text {act }}\right)$ treated as vectors.

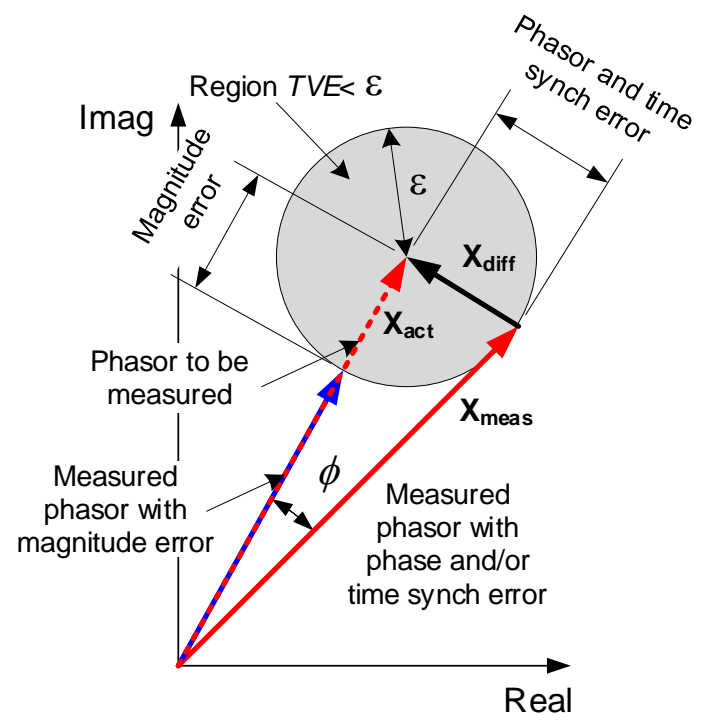

Fig. 3. Graphical representation of the TVE. Based on IEEE C37.118.

\section{PMU Implementations}

IEEE Std C37.118.1-2011 introduced a (non-normative), reference signal processing models (see Fig. 3). The models are used to develop and verify performance requirements presented by the standard.

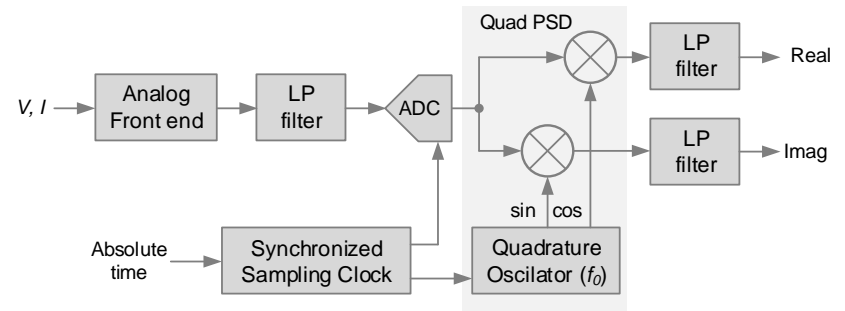

Fig. 4. Single phase section of the PMU phasor signal processing model. $P S D$ : power spectral density.

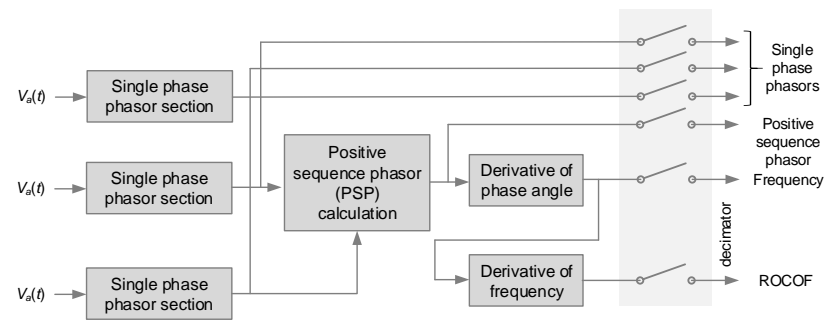

Fig. 5. Complete PMU signal processing model-all processing is shown is at the $\mathrm{A} / \mathrm{D}$ sampling rate; reporting rate is produced by resampling at the system output (decimator stage).
The models depicted in Fig. 3 and 4 are the only representative of a PMU concept. However, industrial PMU has structure not necessarily corresponding to the aforementioned models.

Few external characteristics can be used to create an evident classification on PMU implementations.

The mechanism to receive the GPS signal can be considered as a way to identify PMUs, some equipment uses a remote GPS receiver, and others use an internal GPS. Some commercial manufacturers offer both GPS approaches [19],[20].

Similar situations are found on the PMU manufacturer by Arbiter Systems ${ }^{\circledR}$ Inc.[21] Model 1133A Power Sentinel ${ }^{\mathrm{TM}}$ [21] has an internal GPS receiver and the Model 933A Portable Power SentinelTM [22] uses AS0077600 as remote GPS receiver or equivalent IRIG-B source. The decision of using internal or external GPS receiver is beyond the scope of this paper. A modern tendency is to have an internal receiver in the PMU implementation, e.g. PMU operating alone. A GPS external source or remote receiver is preferred in the case of large installations, i.e. large substation where several PMUs are installed or very low GPS signal is received, in those cases a central GPS signal provider is used.

Another characteristic to take into account when classifying PMU implementations is if the possibility of PMU combined with other functionalities. In this sense, there are two types of PMUs, standalone PMUs and integrated $P M U s$. There is some evidence indicating a standalone PMU is a device that has high accuracy, time-stamped, precision synchronised measurement. Recent time development in micro-electronic allows the integration of multiple functionalities in a compact unit at relatively low cost. As a consequence, an integrated PMU in an Intelligent Electronic Device (IED), can be an embedded function within protection "relays" or disturbance recorders. Schweitzer Engineering Laboratories [19] has a wide range of protection embedded with PMU functionalities such as SEL 311 [23] Line Current Differential Protection and Automation System, SEL 421 [24] Protection, Automation, and Control System, high-speed distance and directional protection and complete control of a two-breaker bay, and SEL-451 [25] Protection, Automation, and Bay Control System.

\section{LOW-Cost PHASOR MEASUREMENT UNIT}

The first PMUs for power grid application were developed in the late 1980s and early 1990s [6], [7], but these were very costly units and made use of proprietary hardware and software interfaces such as LabView [25], which meant that they could not easily be adapted to add functionality or to reduce cost. These implementations were useful for reference purposes and to put the later developments into historical context. When PMU implementation is estimated, there are several aspects to consider: cost, application, location, communication infrastructure, etc.

A typical commercial PMU implementation is produced by big companies dedicated explicitly to PMU (e.g. Arbiter Systems ${ }^{\circledR}$ Inc. [21]) or PMU functionalities embedded in IED, i.e. ABB, SEL, GE, etc. Other companies like ABB also provide multifunctional Intelligent Electronic Devices 
(IEDs) with PMU functionality combined with substation protection functions - RES 670 [11]. The average overall cost per PMU (cost for procurement, installation, and commissioning) ranged from $£ 31,000$ to $£ 150,000$ [26].

There have been a number of successful implementations of PMUs, such as some of the devices of Siemens "Siprotec 5" [27] product line, that performs full integrated functionality, and other fault detection functions not associated with PMU function.

For years, the use of PMU has been dedicated to transmission systems; there are more than 1,000 PMUs installed in the North American transmission system. The immense cost of the power delivery interruptions played the role of initiation for business case for the massive deployment of PMU. The characterizing impedance of the transmission system made the requirement of phase angle (angle differences $>1^{\circ}$ ) less demanding. The reduction in cost and technological advances has made the use of PMU at distribution level a reality. The phrase Micro-PMU has emerged as an identifier of a specifically designed PMU for the distribution system context. However, there are several terms for the PMU application at the distribution level. MicroPMU [28] is a commercial brand from Power Standard Lab. One interesting peculiarity of the PMU installed at distribution level is the fact of strict technical requirements (i.e. Angle differences $<0.1^{\circ}$ ).

Successful implementation is the Power Sensors Ltd. "PQube 3 MicroPMU"[25] which has been installed at $\sim 100$ substations and utility distribution grids under the ARPA-E project, which was started in 2007 to provide funding for initiatives aimed at improving aspects of the USA's energy infrastructure and has a specific project to investigate micro synchrophasor units. Amongst other functions, this device has the ability to store data for one month's worth of measurements and the option to have a 30-minute UPS incorporated. These are expensive systems often costing over $15,000 \$[29]$. This stands as a significant barrier to mass deployment of these devices.

In present days, there are several attempts to produce low-cost PMU at transmission and distribution level, all of that initiative is coming from the academia in an effort to massively use the advantages of the phasor measurements for operation, control and protection.

One of the first initiatives of a low-cost PMU is the called GridTrak $P M U$ produced at Baltimore University and publically available at [30]; DTU PMU [31] was produced in several stages at the Technical University of Denmark. Another initiative on the development of low-cost PMU comes from the European Union-funded IDE4L (Available online: http://ide4l.eu/) named LOCO (LOw COst) PMU [32].

Other more individualised efforts to create a low-cost PMU include Design of an Inexpensive Residential Phasor Measurement Unit [33], MSc Thesis of Mr Onisokonikumen Valiant Sampson [34], MSc thesis of Mr. Debashish Mohapatra [4].

As pointed above, a number of published works describe practical implementations of PMUs, that have been designed and built using open architecture hardware and software, such as Mohapatra [4], the OpenPMU project [35] describes the design and build of a functional PMU, using open source hardware and software in some detail and also includes the code for the software implementation. The OpenPMU project describes the implementation of an OpenPMU design (OpenPMU V1) using National Instruments (NI) hardware and LabView software. There are comprehensive instructions on how to build the device and the implementation of the software to run on it available, making this a useful development tool. However, the use of proprietary hardware makes this an expensive module, especially if the appropriate software licenses are not already held.

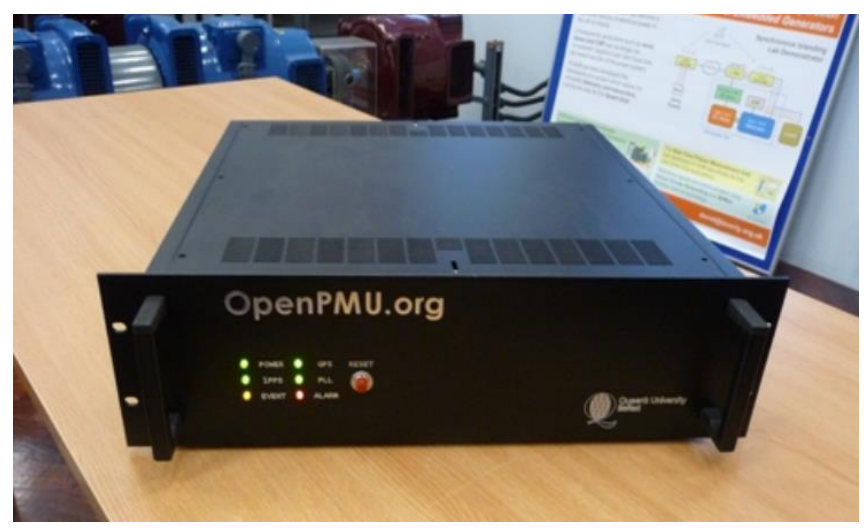

Fig. 6. OpenPMU V1. Photo: Credits to National Instrument[36].

A later version (OpenPMU V2) based on genuinely open source hardware and software is described, but the papers are lacking in the detail of [1], and although pictures of an existing module appear in [11] no instructions for implementing the hardware or software are available.

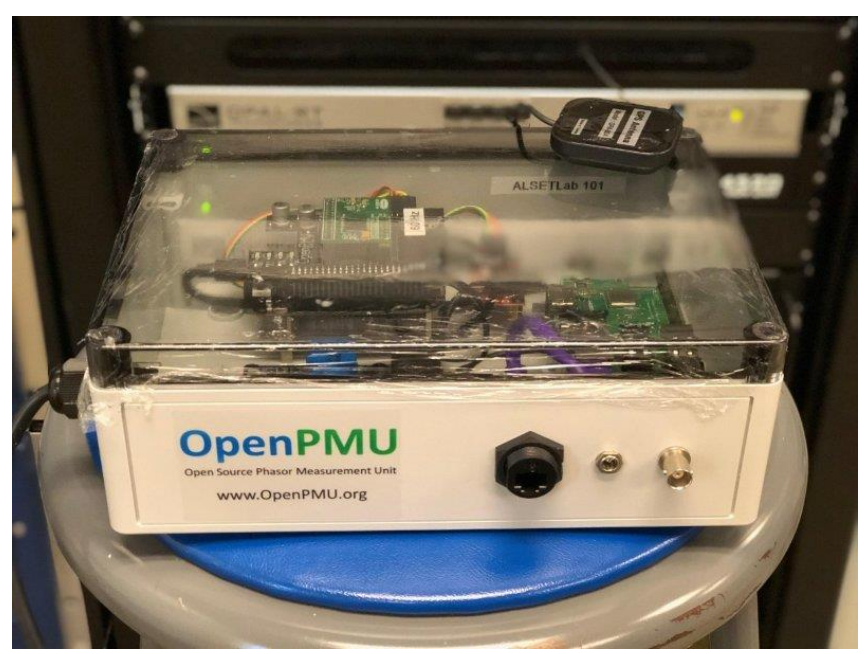

Fig. 7. OpenPMU V2. Photo: Credits to Dr Luigi Vanfretti [37].

Finally, the authors of this paper have focused on a comparison between three open access and low-cost PMU implementations: MSc thesis of Mr. Debashish Mohapatra [4], OpenPMU V1 [4] and OpenPMU V2. Those three projects have data available to produce a realistic comparison in several aspects, and a summary of that comparison is presented in Table I. 
TABLE I. COMPARATIVE RESULTS BETWEEN LOW-COST PMU.

\begin{tabular}{|c|c|c|c|}
\hline PMU Name & OpenPMU V1[38] & $\begin{array}{l}\text { OpenPMU } \\
\text { V2[39] }\end{array}$ & 'Mohapatra' [4] \\
\hline $\begin{array}{c}\text { Approximate } \\
\text { hardware cost }\end{array}$ & $£ 770(2013)[10]$ & $\begin{array}{c}£ 80 \text { without } \\
\text { power interface }\end{array}$ & $£ 400$ \\
\hline $\begin{array}{l}\text { Open-source } \\
\text { hardware }\end{array}$ & $\begin{array}{l}\text { No (uses NI DAQ } \\
\text { module) }\end{array}$ & $\begin{array}{c}\text { Yes } \\
\text { (BeagleBone } \\
\text { Black, custom } \\
\text { DAQ cape) } \\
\end{array}$ & $\begin{array}{l}\text { Yes (Arduino Due, } \\
\text { custom interfaces) }\end{array}$ \\
\hline $\begin{array}{l}\text { Open-source } \\
\text { software }\end{array}$ & $\begin{array}{l}\text { No (uses } \\
\text { LabView) }\end{array}$ & Yes (Linux) & Yes (Linux, Python) \\
\hline $\begin{array}{l}\text { Implementatio } \\
\text { n difficulty }\end{array}$ & $\begin{array}{l}\text { Medium (software } \\
\text { routines available) }\end{array}$ & $\begin{array}{l}\text { Hard (no details } \\
\text { of exact } \\
\text { configuration or } \\
\text { software routines } \\
\text { available) }\end{array}$ & $\begin{array}{l}\text { Medium (software } \\
\text { routines available, } \\
\text { hardware description } \\
\text { not complete) }\end{array}$ \\
\hline Comments & $\begin{array}{c}\text { Not practical due } \\
\text { to proprietary } \\
\text { hardware and } \\
\text { software } \\
\text { platforms. }\end{array}$ & $\begin{array}{l}\text { This is the most } \\
\text { promising long- } \\
\text { term option. } \\
\text { However, Dr } \\
\text { Laverty } \\
\text { contacted but no } \\
\text { information yet } \\
\text { forthcoming. }\end{array}$ & $\begin{array}{l}\text { More complex and } \\
\text { expensive than } \\
\text { OpenPMU2 (uses } 3 \mathrm{x} \\
\text { processors) and needs } \\
\text { an external PC for } \\
\text { processing and } \\
\text { display. However, this } \\
\text { is the most expedient } \\
\text { option. }\end{array}$ \\
\hline $\begin{array}{c}\text { Score } \\
(1=\text { low, } \\
3=\text { high })\end{array}$ & $\begin{array}{c}\text { Cost: } 1 \\
\text { Open-source: } 1 \\
\text { Availability: } 2\end{array}$ & $\begin{array}{c}\text { Cost: } 3 \\
\text { Open-source: } 3 \\
\text { Availability: } 1\end{array}$ & $\begin{array}{c}\text { Cost: } 2 \\
\text { Open-source: } 3 \\
\text { Availability: } 3\end{array}$ \\
\hline
\end{tabular}

\section{CONCLUSIONS}

The analysed information for the available on the market industrial PMUs indicates that the cost for implementation of the synchrophasor measurement technology has been reduced during the last years, but still quite significant to implement widely in peripheral distribution and subdistribution electrical power networks.

The development of "budget oriented" PMU module can enhance the monitoring and control of different consumers and generators, which in result of their limited capacity do not affect the grid behaviour, but have specific importance in respect of their functionality. "Low-cost" PMU (but definitely hardware reliable and software compatible), can be used as source of precise timing in different infrastructure facilities, where time stamping, and centralized time synchronization can be required. Contemporary autonomous quartz stabilized clocks are widely used, they have a sufficient preciseness for many applications, but still may need periodical adjustment.

The combination of PMU used to measure some parameters in point of distribution grid, providing timing synchronization may solve problems related to control systems of highway facilities, tunnels, specific infrastructure related to railroad transport, etc. For locations in mountains where the "horizon" for satellite signals can be problematic and there are periods during the $24 \mathrm{~h}$ day profile, when no GPS signal is received - the timing shall be obligatory backupped with built in autonomous clock, which shall be with correction option when the satellite receiving is reestablished.

\section{ACKNOWLEDGEMENT}

The author of this paper would like to express his gratitude to Mr Debashish Mohapatra whose paper was used to provide the detail for the 'baseline' PMU used.

\section{REFERENCES}

[1] H. R. Chamorro, A. C. Sanchez, A. Pantoja, I. Zelinka, F. GonzalezLongatt, and V. K. Sood, "A network control system for hydro plants to counteract the non-synchronous generation integration," Int. J. Electr. Power Energy Syst., vol. 105, pp. 404-419,.

[2] F. Harold R. Chamorro, Camilo A. Ordones, Jimmy C-H. Peng and G.-L. and V. K. Sood, "Coherency Estimation in Power Systems: A Koopman Operator Approach," in Computational Intelligence and Optimization Methods for Control Engineering, 2018.

[3] F. Sanchez, F. Gonzalez-Longatt, and D. Bogdanov, "Impact Assessment of Frequency Support by Electric Vehicles: Great Britain Scenario 2025," in XXth International Symposium on Electrical Apparatus and Technologies, SIELA 2018, 2018, pp. 1-8.

[4] D. Mohapatra, "Development and Hardware Implementation of a Phasor Measurement Unit using Microcontroller Master of Technology," National Institute of Technology, Rourkela.

[5] A. G. Phadke, M. Ibrahim, and T. Hlibka, "Fundamental basis for distance relaying with symmetrical components," IEEE Trans. Power Appar. Syst., vol. 96, no. 2, pp. 635-646, Mar. 1977.

[6] A. G. Phadke and J. S. Thorp, "History and applications of phasor measurements," 2006 IEEE PES Power Syst. Conf. Expo. PSCE 2006 - Proc., pp. 331-335, 2006.

[7] A. G. Phadke, "Synchronized phasor measurements-a historical overview," in IEEE/PES Transmission and Distribution Conference and Exhibition, vol. 1, pp. 476-479.

[8] L. Vanfretti and J. H. Chow, "Synchrophasor Data Applications for Wide-Area Systems *," Syst. Eng., 2011.

[9] E. Society, IEEE Standard for Synchrophasor Measurements for Power Systems IEEE Power \& Energy Society, vol. 2011, no. December. 2012.

[10] C. P. Steinmetz, "Complex Quantities and their use in Electrical Engineering," AIEE Proceedings of International Electrical Congress. pp. 33-74, 1893.

[11] Power Systems Relay Committee of the IEEE Power Engineering Society, IEEE Standard for Common Format for Event Data Exchange ( COMFEDE ) for Power Systems. 1999.

[12] IEC, "IEC61850-2013: Communication networks and systems for power utility automation," 2013.

[13] "IEEE Standard for Synchrophasers for Power Systems," IEEE Std 1344-1995(R2001), p. i-, 1995.

[14] G. Benmouyal et al., "An Overview of the IEEE Standard C37.118.2-Synchrophasor Data Transfer for Power Systems," IEEE Trans. Smart Grid, vol. 5, no. 4, 2014.

[15] IEEE Power \& Energy Society, IEEE Std C37.118.1-2011. IEEE Standard for Synchrophasor Measurements for Power Systems, vol. 2011, no. December. 2011.

[16] IEEE Power and Energy Society, IEEE Std C37.118.2-2011 - IEEE Standard for Synchrophasor Data Transfer for Power Systems, vol. 2011, no. December. 2011.

[17] P. System, R. Committee, I. Power, and E. Society, "IEEE Standard for Synchrophasor Measurements for Power Systems -- Amendment 1: Modification of Selected Performance Requirements," IEEE Std C37.118.1a-2014 (Amendment to IEEE Std C37.118.1-2011), vol. 2014, pp. 1-25, 2014.

[18] D. Schofield, "Development And Implementation Of A Reduced Cost Phasor Measurement Unit (PMU)," Loughborough University, 2018.

[19] “SEL - Schweitzer Engineering Laboratories." [Online]. Available: https://selinc.com/. [Accessed: 04-Sep-2018].

[20] ABB "RES670 - Phasor measurement unit For real-time and efficient wide area power system monitoring, protection and control" available at . https://new.abb.com/substation-automation/products/ protection-control/phasor-measurement/res670;

[21] "MODEL 1133A POWER SENTINEL GPS-SYNCHRONIZED POWER QUALITY REVENUE STANDARD OPERATION MANUAL."

[22] "Model 933A Portable Power Sentinel ${ }^{\mathrm{TM}}$ Operation Manual."

[23] "SEL-311L Line Current Differential Protection and Automation System | Schweitzer Engineering Laboratories." [Online]. Available: https://selinc.com/products/311L/. [Accessed: 04-Sep-2018]. 
[24] "SEL-421 Protection, Automation, and Control System | Schweitzer Engineering Laboratories." [Online]. Available: https://selinc.com/products/421/. [Accessed: 04-Sep-2018].

[25] "SEL-451 Protection, Automation, and Bay Control System | Schweitzer Engineering Laboratories." [Online]. Available: https://selinc.com/products/451/. [Accessed: 04-Sep-2018].

[26] US Department of Energy, "Factors Affecting PMU Installation Costs," 2014.

[27] "SIPROTEC 7KE85 - Fault Recorder - Digital Grid - Siemens."

[28] "Highlights - Power Standards Lab." [Online]. Available: https://www.powerstandards.com/product/micropmu/highlights/. [Accessed: 04-Sep-2018].

[29] D. M. Laverty, L. Vanfretti, I. Al Khatib, V. K. Applegreen, R. J. Best, and D. J. Morrow, "The OpenPMU Project: Challenges and perspectives," in 2013 IEEE Power \& Energy Society General Meeting, 2013, pp. 1-5.

[30] “Open Source SynchroPhasor PMU - CodePlex Archive." [Online]. Available: https://archive.codeplex.com/?p=gridtrak. [Accessed: 04Sep-2018].

[31] R. Garcia-Valle, G. Y. Yang, K. E. Martin, A. H. Nielsen, and J. Ostergaard, "DTU PMU laboratory development - Testing and validation," IEEE PES Innov. Smart Grid Technol. Conf. Eur. ISGT Eur., pp. 1-6, 2010.
[32] A. Angioni, G. Lipari, M. Pau, F. Ponci, and A. Monti, "A Low Cost PMU to Monitor Distribution Grids," AMPS 2017 - IEEE Int. Work. Appl. Meas. Power Syst. Proc., 2017.

[33] J. Vick, "Design of an Inexpensive Residential Phasor Measurement Unit," 2014.

[34] O. Sampson, "Construction of a phasor measurement unit (PMU) for power system applications," 2015.

[35] "OpenPMU." [Online]. Available: https://sites.google.com/site/openpmu/. [Accessed: 04-Sep-2018].

[36] "OpenPMU: The Open-Source Phasor Measurement Unit - Solutions - National Instruments." [Online]. Available: http://sine.ni.com/cs/app/doc/p/id/cs-14787\#prettyPhoto[gallery]/0/. [Accessed: 04-Sep-2018].

[37] "Luigi Vanfretti - Associate Professor - Rensselaer Polytechnic Institute | LinkedIn.” [Online]. Available: https://www.linkedin.com/in/vanfretti. [Accessed: 04-Sep-2018].

[38] D. M. Laverty, L. Vanfretti, R. J. Best, D. J. Morrow, L. Nordstrom, and M. Chenine, "OpenPMU technology platform for Synchrophasor research applications," in 2012 IEEE Power and Energy Society General Meeting, 2012, pp. 1-5.

[39] X. Zhao, D. M. Laverty, A. McKernan, D. J. Morrow, K. McLaughlin, and S. Sezer, "GPS-Disciplined Analog-to-Digital Converter for Phasor Measurement Applications," IEEE Trans. Instrum. Meas., vol. 66, no. 9, pp. 2349-2357, Sep. 2017. 